\title{
THE STATISTICAL THEORY OF MONOMOLECULAR FULLERENE FILM FORMATION ON THE CRYSTAL SURFACE
}

\author{
Matysina Z.A., Zaginaichenko S.Yu. *, and Schur D.V. \\ *Author for correspondence \\ Institute for Problems of Materials Science of NAS of Ukraine, \\ Krzhyzhanovsky str. 3, \\ Kiev, 03142, \\ Ukraine; \\ Tel./Fax: 38-044-424-03-81; \\ E-mail: shurzag@ipms.kiev.ua
}

\begin{abstract}
The theoretical study of fullerene film production on the crystal faces of (100) type of crystals with sc, bcc, fcc lattices is the subject of this paper. The calculation of equilibrium concentration of fullerenes $\mathrm{C}_{60}, \mathrm{C}_{70}$ and its dependence on temperature has been carried out. Investigation of processes adsorption-desorption of fullerenes on the crystal surface and possible special features of these processes has been discussed. The developed statistical theory of the process of fullerenes deposition on the metallic substrate permits to explain and justify the possibility of manifestation of these processes and reveal that passing of each process is defined to a large extent by the character and degree of interaction between fullerenes and atoms of metallic substrate.
\end{abstract}

\section{INTRODUCTION}

Experimental investigation of process of fullerenes deposition on the metallic substrate allows to establish its common character as well as some features. The fullerenes $\mathrm{C}_{60}$ deposition on the crystals of noble metals, refractory and some non-metals as Ir, Mo, Ni, Re, W, Si etc. have been investigated [1-16]. It has been found experimentally that molecules $C_{60}$ hold their shape and structure up to the certain temperature, which value depends on the chemical nature of substrate. As it turned out this temperature is the lowest for tungstem W (300 $\mathrm{K})$. In addition on the Mo, Ir, Re substrate the close-packed monomolecular layer is formed at the room temperature, on the surface of $\mathrm{Ni}$, Si crystals the formation of crystallites of tower type occurs. The deposition on the faces of Mo, W crystals gave the layer-by-layer growth of film from 6-10 monomolecular layers. In the case of molybdenum substrate the temperature rise stimulated the process of thermodesorption of fullerenes.
Our interest is in theoretical investigation of fullerene film formation on the crystal faces, the evaluation of equilibrium concentration of fullerenes, its temperature dependence, study of adsorption-desorption processes, the establishment of possible peculiarities of these processes.

\section{NOMENCLATURE}

$\begin{array}{lll}a, b & {[\mathrm{~nm}]} & \text { Lattice constant } \\ d & {[\mathrm{~nm}]} & \text { Fullerene diameter } \\ c & {[-]} & \text { Equilibrium concentration } \\ k & {[\mathrm{eV} / \mathrm{K}]} & \text { Boltzmann constant } \\ F & {[\mathrm{eV}]} & \text { Free energy of crystal } \\ E & {[\mathrm{eV}]} & \text { Configuration energy } \\ T & {[\mathrm{~K}]} & \text { Temperature } \\ G & {[-]} & \text { Thermodynamic probability } \\ N & {[-]} & \text { Number of lattice sites (fullerenes) in monofilm } \\ c & {[-]} & \text { Total concentration of fullerenes } \\ v_{\Phi}, v_{M} & {[\mathrm{eV}]} & \text { Energies of } \Phi \Phi \text { and } \Phi M \text { pairs interaction } \\ c_{1}, c_{2} & {[-]} & \text { Concentrations of fullerenes } \mathrm{C}_{60}, \mathrm{C}_{70} \\ c_{V} & {[-]} & \text { Concentrations of vacant sites in monofilm }\end{array}$

To solve these problems the calculation of free energy has been performed, the fullerenes concentration has been determined from equilibrium conditions, the special features of its temperature dependence has been ascertained, the character of fullerenes interaction with crystals atoms and inter-fullerene interaction have been investigated. In calculations the formation of monomolecular film of fullerenes $\Phi_{1}=\mathrm{C}_{60}$, $\Phi_{2}=C_{70}$ without considering their ordering. It has been accepted that the face of crystal substrate has a square symmetry. This is the face of (100) type of crystals with sc, bcc, fcc lattices. The model of spherically symmetric hard spheres $[17,18]$, the method of average energies $[19,20]$ and 
the approach of interaction of the nearest fullerene pairs and the substrate atoms with fullerenes have been used in calculations. It has been also assumed the geometrical ideality of crystal structures of both fullerene monofilm and substrate.

The structure of monomolecular film of fullerenes and substrate face (100) in projection on the considered face is shown in Figure 1. The figure has been made on the basis of geometry of bcc crystal structure of substrate, the dimensional values of the lattice parameters $a$ of metal [21], 8 of fullerene $[22,23]$ and structure-chemical diameter $d$ of fullerene [24], which are equal to (in $\mathrm{nm}$ ): $a=0,315$ (for Mo), $6=1,42$, $d=0,85$. Fullerenes are located in the wells of a square lattice of crystal face (100). It is evident from Fig. 1 that each fullerene is surrounded by four nearest fullerenes and four nearest atoms of the crystal substrate.

\section{FREE ENERGY OF FULLERITE. EQUATIONS OF EQUILIBRIUM}

The free energy is calculated by the formula $[19,20]$

$$
\mathrm{F}=\mathrm{E}-\mathrm{k} \mathrm{T} \ln \mathrm{G} \text {, }
$$

where $\mathrm{E}$ is configuration internal energy defined by the sum of energies of pair interaction of the nearest fullerenes $\Phi_{i} \Phi_{j}(i, j=$ $1,2)$ and fullerenes with atoms of the substrate $\Phi_{i} M ; G$ is the thermodynamic probability of distribution of fullerenes of different type in the monomolecular film (in this case some positions of monofilm can be vacant, which we denote by the symbol V), $\mathrm{k}$ is Boltzmanns constant, $\mathrm{T}$ is absolute temperature.

In the used approximation we get the formula for the configuration energy $\mathrm{E}$

$$
E=-\sum_{i, j=1,2} N_{\Phi_{i} \Phi_{j}} v_{\Phi_{i} \Phi_{j}}+N_{\Phi_{i} M} \cup_{\Phi_{i} M}, \quad i, j=1,2,
$$

where $\mathrm{N}_{\Phi_{\mathrm{i}} \Phi_{\mathrm{j}}}$ and $\mathrm{N}_{\Phi_{\mathrm{i}} \mathrm{M}}$ are the numbers of nearest pairs of fullerenes $\Phi_{\mathrm{i}}, \Phi_{\mathrm{j}}$ and pairs of fullerenes with atoms of metallic substrate $\Phi_{\mathrm{i}} \mathrm{M}, v_{\mathrm{ij}}=v_{\Phi_{\mathrm{i}} \Phi_{\mathrm{j}}}, v_{\mathrm{iM}}=v_{\Phi_{\mathrm{i}} \mathrm{M}}$ are energies with the opposite sign for interaction of these pairs.

According to the combinatorics rules thermodynamic probability $\mathrm{G}$ is defined by equation

$$
\mathrm{G}=\frac{\mathrm{N} !}{\mathrm{N}_{\Phi_{1}} ! \mathrm{N}_{\Phi_{2}} ! \mathrm{N}_{\mathrm{V}} !},
$$

where $\mathrm{N}$ is the number of sites of monofilm, $\mathrm{N}_{\Phi_{1}}, \mathrm{~N}_{\Phi_{2}}, \mathrm{~N}_{\mathrm{V}}$ are the numbers of these sites occupied by fullerenes $\Phi_{1}, \Phi_{2}$ respectively and being vacant.

The numbers of $\Phi_{\mathrm{i}} \Phi_{\mathrm{j}}, \Phi_{\mathrm{i}} \mathrm{M}$ pairs in accordance with the structure (Fig .1) are equal, respectively

$$
\begin{aligned}
& \mathrm{N}_{\Phi_{1} \Phi_{1}}=2 \mathrm{~N}_{\Phi_{1}}^{2} / \mathrm{N}, \quad \mathrm{N}_{\Phi_{2} \Phi_{2}}=2 \mathrm{~N}_{\Phi_{1}}^{2} / \mathrm{N}, \\
& \mathrm{N}_{\Phi_{1} \Phi_{2}}=4 \mathrm{~N}_{\Phi_{1}} \mathrm{~N}_{\Phi_{2}} / \mathrm{N}, \\
& \mathrm{N}_{\Phi_{1} \mathrm{M}}=4 \mathrm{~N}_{\Phi_{1}}, \quad \mathrm{~N}_{\Phi_{2} \mathrm{M}}=4 \mathrm{~N}_{\Phi_{2}},
\end{aligned}
$$

where

$$
\mathrm{N}=\mathrm{N}_{\Phi_{1}}+\mathrm{N}_{\Phi_{2}}+\mathrm{N}_{\mathrm{V}}
$$

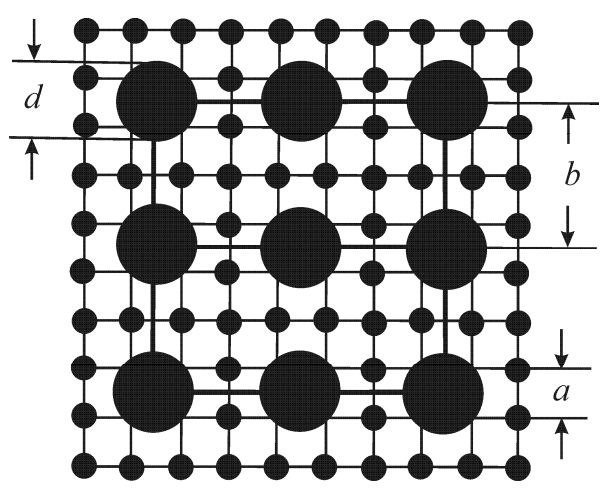

Figure 1 The structure of fullerite monomolecular film on the face (100) of crystal. $a$ and $b$ are lattice parameters of crystal and fullerite respectively, $d$ is structure-chemical diameter of fullerene.

- sites occupied by fullerenes $\Phi_{1}=\mathrm{C}_{60}, \Phi_{2}=\mathrm{C}_{70}, \mathrm{C}_{70}, \Phi_{2}$

- sites of the crystal face

We find the natural logarithm of thermodynamic probability $G$ from formula (.3), using Stirling formula $\ln X !=X(\ln X-1)$ for large $X$ numbers:

$$
\begin{aligned}
\ln \mathrm{G} & =\mathrm{N} \ln \mathrm{N}-\mathrm{N}_{\Phi_{1}} \ln \mathrm{N}_{\Phi_{1}}- \\
& -\mathrm{N}_{\Phi_{2}} \ln \mathrm{N}_{\Phi_{2}}-\mathrm{N}_{\mathrm{V}} \ln \mathrm{N}_{\mathrm{V}}
\end{aligned},
$$

in doing so we take into account the relation (5).

Substituting values of $E(2)$ and $\ln G(6)$ in $F(1)$ in terms of (4), (5) we find free energy as follows:

$$
\begin{aligned}
\mathrm{F}= & -\frac{2}{\mathrm{~N}_{\Phi_{1}}+\mathrm{N}_{\Phi_{2}}+\mathrm{N}_{\mathrm{V}}}\left(\mathrm{N}_{\Phi_{1}}^{2} \mathrm{v}_{11}+\mathrm{N}_{\Phi_{2}}^{2} \mathrm{v}_{22}+2 \mathrm{~N}_{\Phi_{1}} \mathrm{~N}_{\Phi_{2}} \mathrm{v}_{12}\right)- \\
& -4\left(\mathrm{~N}_{\Phi_{1}} \mathrm{v}_{1 \mathrm{M}}+\mathrm{N}_{\Phi_{2}} \mathrm{v}_{2 \mathrm{M}}\right) /\left(\mathrm{N}_{\Phi_{1}}+\mathrm{N}_{\Phi_{2}}+\mathrm{N}_{\mathrm{V}}\right)- \\
& -\mathrm{kT}\left[\left(\mathrm{N}_{\Phi_{1}}+\mathrm{N}_{\Phi_{2}}+\mathrm{N}_{\mathrm{V}}\right) \ln \left(\mathrm{N}_{\Phi_{1}}+\mathrm{N}_{\Phi_{2}}+\mathrm{N}_{\mathrm{V}}\right)-\right. \\
& \left.-\mathrm{N}_{\Phi_{1}} \ln \mathrm{N}_{\Phi_{1}}-\mathrm{N}_{\Phi_{2}} \ln \mathrm{N}_{\Phi_{2}}-\mathrm{N}_{\mathrm{V}} \ln \mathrm{N}_{\mathrm{V}}\right] .
\end{aligned}
$$

In the equilibrium state the free energy should be minimal. The conditions for minimum of free energy are easily found by the method of the indeterminate Lagrange factor $\lambda$. Factor $\lambda$ is correlated with the equation (5) of the relation between numbers $\mathrm{N}_{\Phi_{1}}, \mathrm{~N}_{\Phi_{2}}, \mathrm{~N}_{\mathrm{V}}$. For this we make up the function

$$
\Phi=\mathrm{F}+\lambda\left(\mathrm{N}_{\Phi_{1}}+\mathrm{N}_{\Phi_{2}}+\mathrm{N}_{\mathrm{V}}-\mathrm{N}\right) .
$$

In this case the conditions for minimum of free energy are written as follows:

$$
\partial \Phi / \partial \mathrm{N}_{\Phi_{1}}=0, \quad \partial \Phi / \partial \mathrm{N}_{\Phi_{2}}=0, \quad \partial \Phi / \partial \mathrm{N}_{\mathrm{V}}=0 .
$$

The conditions (9) give the equations

$$
\begin{aligned}
& \frac{2}{\mathrm{~N}^{2}}\left(\mathrm{~N}_{\Phi_{1}}^{2} \mathrm{v}_{11}+\mathrm{N}_{\Phi_{2}}^{2} \mathrm{v}_{22}+2 \mathrm{~N}_{\Phi_{1}} \mathrm{~N}_{\Phi_{2}} \mathrm{v}_{12}\right)- \\
& -\frac{4}{\mathrm{~N}}\left(\mathrm{~N}_{\Phi_{1}} \mathrm{v}_{11}+\mathrm{N}_{\Phi_{2}} \mathrm{v}_{12}\right)-4 \mathrm{v}_{1 \mathrm{M}}- \\
& -\mathrm{kT}\left(\ln \mathrm{N}-\ln \mathrm{N}_{\Phi_{1}}\right)+\lambda=0,
\end{aligned}
$$




$$
\begin{aligned}
& \frac{2}{\mathrm{~N}^{2}}\left(\mathrm{~N}_{\Phi_{1}}^{2} \mathrm{v}_{11}+\mathrm{N}_{\Phi_{2}}^{2} \mathrm{v}_{22}+2 \mathrm{~N}_{\Phi_{1}} \mathrm{~N}_{\Phi_{2}} \mathrm{v}_{12}\right)- \\
& -\frac{4}{\mathrm{~N}}\left(\mathrm{~N}_{\Phi_{2}} \mathrm{v}_{22}+\mathrm{N}_{\Phi_{1}} \mathrm{v}_{12}\right)-4 \mathrm{v}_{2 \mathrm{M}}- \\
& -\mathrm{kT}\left(\ln \mathrm{N}-\ln \mathrm{N}_{\Phi_{2}}\right)+\lambda=0, \\
& \frac{2}{\mathrm{~N}}\left(\mathrm{~N}_{\Phi_{1}}^{2} \mathrm{v}_{11}+\mathrm{N}_{\Phi_{2}}^{2} \mathrm{v}_{22}+2 \mathrm{~N}_{\Phi_{1}} \mathrm{~N}_{\Phi_{2}} \mathrm{v}_{12}\right)- \\
& \quad-\mathrm{kT}\left(\ln \mathrm{N}-\ln \mathrm{N}_{\mathrm{V}}\right)+\lambda=0 .
\end{aligned}
$$

From formulae (10) - (12) we form the relations $(10)+(11)-2 \cdot(12)$, (10) - (11). We find two equations, potentiating which together with (5), we receive

$$
\begin{aligned}
\frac{c_{1} c_{2}}{c_{V}^{2}} & =\exp \frac{4}{k T}\left[\left(v_{11}+v_{12}\right) c_{1}+\right. \\
& \left.+\left(v_{12}+v_{22}\right) c_{2}+v_{1 M}+v_{2 M}\right], \\
\frac{c_{1}}{c_{2}} & =\exp \frac{4}{k T}\left[\left(v_{11}-v_{12}\right) c_{1}+\right. \\
& \left.+\left(v_{12}-v_{22}\right) c_{2}+v_{1 M}-v_{2 M}\right], \\
c_{1} & +c_{2}+c_{V}=1,
\end{aligned}
$$

where

$$
\mathrm{c}_{1}=\mathrm{N}_{\Phi_{1}} / \mathrm{N}, \quad \mathrm{c}_{2}=\mathrm{N}_{\Phi_{2}} / \mathrm{N}, \quad \mathrm{c}_{\mathrm{V}}=\mathrm{N}_{\mathrm{V}} / \mathrm{N}
$$

are concentrations of fullerenes $\Phi_{1}, \Phi_{2}$ and vacant sites in the monomolecular layer.

The derived formulae (13)-(15) determine the equilibrium concentrations of fullerenes in dependence on temperature and energetic parameters.

To solve the system of equations (13)-(15) it is convenient to get more simple equations forming such formulae: (13) $\cdot(14)$ and (13): (14). As a result we find

where

$$
\mathrm{c}_{1} / \mathrm{c}_{\mathrm{V}}=\mathrm{e}_{1}, \quad \mathrm{c}_{2} / \mathrm{c}_{\mathrm{V}}=\mathrm{e}_{2}
$$

$$
\begin{aligned}
& \mathrm{e}_{1}=\exp \frac{4}{\mathrm{kT}}\left(\mathrm{v}_{11} \mathrm{c}_{1}+\mathrm{v}_{12} \mathrm{c}_{2}+\mathrm{v}_{1 \mathrm{M}}\right) \\
& \mathrm{e}_{2}=\exp \frac{4}{\mathrm{kT}}\left(\mathrm{v}_{12} \mathrm{c}_{1}+\mathrm{v}_{22} \mathrm{c}_{2}+\mathrm{v}_{2 \mathrm{M}}\right)
\end{aligned}
$$

Formulae (17), (18) and (15) allow us to find

$$
\begin{gathered}
\mathrm{c}_{\mathrm{V}}=\left(1+\mathrm{e}_{1}+\mathrm{e}_{2}\right)^{-1}, \mathrm{c}_{1}=\mathrm{e}_{1}\left(1+\mathrm{e}_{1}+\mathrm{e}_{2}\right)^{-1}, \\
\mathrm{c}_{2}=\mathrm{e}_{2}\left(1+\mathrm{e}_{1}+\mathrm{e}_{2}\right)^{-1},
\end{gathered}
$$

determining the temperature dependence of equilibrium concentrations of fullerenes $\Phi_{1}, \Phi_{2}$ in monomolecular film on the crystal surface.

\section{DISCUSSION OF RESULTS}

The derived formulae (19), (18) enable us to study the adsorption-desorption of fullerenes under changes of temperature. In the adsorption process the concentrations $\mathrm{c}_{1}, \mathrm{c}_{2}$ are bound to increase, but $\mathrm{c}_{\mathrm{V}}$ to decrease. If at any temperature the fullerenes desorption process will manifests itself, the concentrations $\mathrm{c}_{1}, \mathrm{c}_{2}$, on the contrary, will diminish, but $\mathrm{c}_{\mathrm{V}}$ will increase. As this takes place, the extremum will present on the $\mathrm{c}_{1}(\mathrm{~T}), \mathrm{c}_{2}(\mathrm{~T}), \mathrm{c}_{\mathrm{V}}(\mathrm{T})$ curves.

From the extreme conditions

$$
\partial \mathrm{c}_{\mathrm{V}} / \partial \mathrm{T}=0
$$

we find that

$$
\begin{aligned}
& \frac{v_{11} c_{1}+v_{12} c_{2}+v_{1 M}}{v_{12} c_{1}+v_{22} c_{2}+v_{2 M}}=-\exp \left[\left(v_{12}-v_{11}\right) c_{1}+\right. \\
& \left.+\left(v_{22}-v_{12}\right) c_{2}+v_{2 M}-v_{1 M}\right]<0 .
\end{aligned}
$$

Since the exponential function is positive, then extremum can take place at the condition of negative values of the left side of equation (21), which can be realized in the case of negative values of some energetic parameters. More precisely the following inequalities must be satisfied

$$
\begin{aligned}
& v_{11}<v_{12}<v_{22}, \quad v_{1 M}<v_{2 M} \\
& \text { or } \quad v_{11}>v_{12}>v_{22}, \quad v_{1 M}>v_{2 M} .
\end{aligned}
$$

This is necessary but not sufficient conditions for the extremum manifestation on the curves $c_{1}(T), c_{2}(T)$, i.e. of adsorption-desorption processes.

In the particular case of deposition of monosort fullerene, $\Phi=\mathrm{C}_{60}$ as an example, on the crystal substrate, its equilibrium concentration is defined by formula

$$
\mathrm{c}=\left[1+\exp \frac{-4\left(\mathrm{cv}_{\Phi}+v_{M}\right)}{\mathrm{kT}}\right]^{-1}
$$

where $v_{\Phi}$ and $v_{M}$ are energies of interaction of $\Phi \Phi$ and $\Phi M$ pairs.

The condition of extremality in this case gives the value $c_{e}$ equal to

$$
c_{\mathrm{e}}=-v_{\mathrm{M}} / \mathrm{v}_{\Phi},
$$

whence one can see that desorption makes itself evident at energies $v_{\Phi}, v_{M}$ of different signs. We shall note that condition (24) is necessary, but not sufficient.

As an example we have constructed the plots of temperature dependence of equilibrium concentration of fullerene $\Phi \mathrm{c}=\mathrm{c}(\mathrm{T})$ for different values of energetic parameters $v_{\Phi}, v_{M}$. We have used the graphical method of definition of concentration $c$ for different temperatures. We denote the left and right sides of equation (23) by characters

$$
\mathrm{f}_{1}=\mathrm{c}, \quad \mathrm{f}_{2}=\left[1+\exp \frac{-4\left(\mathrm{cv}_{\Phi}+\mathrm{v}_{\mathrm{M}}\right)}{\mathrm{kT}}\right]^{-1} .
$$

At the preassigned possible values of concentration $c$ in the range $0 \leq \mathrm{c} \leq 1$, we construct the plots $\mathrm{f}_{1}=\mathrm{f}_{1}(\mathrm{c})$ and $\mathrm{f}_{2}=\mathrm{f}_{2}(\mathrm{c})$ for different temperatures $\mathrm{T}$ and find the intersection points of these graphs that define the concentration value $c$ for each temperature and as a result the dependence $\mathrm{c}=\mathrm{c}(\mathrm{T})$.

The graphic example of such definition of values $c$ at different temperatures is shown in Fig.2. The intersection points of curves $f_{1}(c)$ and $f_{2}(c)$ (25), marked by circles, define the equilibrium concentration of fullerenes for temperatures $\mathrm{kT}=0,04$; 0,$2 ; 0,5 ; 0,8 ; 1 \mathrm{eV}$ and energetic parameters equal to $\mathrm{v}_{\Phi}=-0,03$ $\mathrm{eV}, \mathrm{v}_{\mathrm{M}}=0,01 \mathrm{eV}$. The found dependence $\mathrm{c}=\mathrm{c}(\mathrm{T})$ in this case is shown by the graph $(a)$ in the Fig. 3 . 
Figure 3 illustrates also the curve of dependence $\mathrm{c}=\mathrm{c}(\mathrm{T})$, constructed for another values of energetic parameters $v_{\Phi}, v_{\mathrm{M}}$. As can be seen from Figure 3, in the cases $(a)$ и (b), when energetic parameters $v_{\Phi}, v_{M}$ are of different signs, but value $v_{M}$ is positive and small (weak interaction between fullerenes and atoms of metallic substrate of the attraction type), the function $\mathrm{c}=\mathrm{c}(\mathrm{T})$ increases monotonically and extremality is missing. These cases correspond to the adsorption of fullerenes on the crustal surface. In the cases $(c),(d),(e),(f)$, when fullerenes interaction with atoms of substrate increases, the energy $v_{M}$ undergoes a rise and the character of interaction between fullerenes and metallic atoms is of repulsive type $\left(v_{M}<0\right)$ the extremality shows itself on the curves of temperature dependence of fullerene concentrations in the monomolecular film. The first peak on the curves is marked by circle. The numerical values of concentration and temperature, corresponding to this maximum, according to (24) and formula (23) are equal to

$$
\begin{aligned}
& \text { (c) } \mathrm{c}_{\mathrm{m}}=0,61, \\
& \mathrm{kT}_{\mathrm{m}}=0,1 \mathrm{eV}, \\
& \text { (d) } \mathrm{c}_{\mathrm{m}}=0,68, \mathrm{kT}_{\mathrm{m}}=0,2 \mathrm{eV}, \\
& \text { (e) } \mathrm{c}_{\mathrm{m}}=0,63, \\
& \text { (f) } \mathrm{kT}_{\mathrm{m}}=0,70,15 \mathrm{eV},
\end{aligned}
$$

In these cases with a rise in temperature up to $T=T_{m}$ the adsorption process goes and then at $T>T_{m}$ the desorption of fullerenes must occur (authors of [16] called it as thermodesorption). In practice the hysteresis phenomena are possible when the desorption manifests itself or not manifests at all. This is possible, if fullerenes deposition is a large flow and goes over a long period of time as well as depending on the speed of deposited fullerenes. The plots of dependence $\mathrm{c}(\mathrm{T})$ can be smoothed as shown by the dashed curves in Fig. $3(c),(d)$, $(e)$. In the case of $(f)$ at the sufficiently high energy $v_{M}$ even the curve smoothing leads to the desorption process.

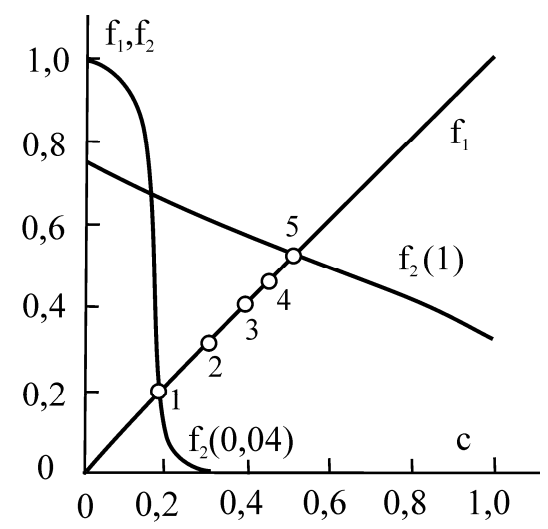

Figure 2 For the calculation of temperature dependence of fullerenes concentration of monomolecular film on the crystal surface. The extreme curves $f_{2}(c)$ are shown for temperatures $\mathrm{kT}=0,04 \mathrm{eV}$ and $1 \mathrm{eV}$ and energetic parameters equal to $\mathrm{v}_{\Phi}=-0,03 \mathrm{eV}, \mathrm{v}_{\mathrm{M}}=0,01 \mathrm{eV}$
The points corresponding to the intersections of curves $f_{1}$, $\mathrm{f}_{2}$ in Fig. 2 are marked by numbers $1-5$ on the curve $(a)$. In the case of hysteresis phenomena the possible run of curves is shown by dashed lines.

The experimental points, in which $\mathrm{c}_{\mathrm{m}}=-\mathrm{v}_{\mathrm{M}} / \mathrm{v}_{\Phi}$, are marked by circles on the curves $(c),(d),(e),(f)$.
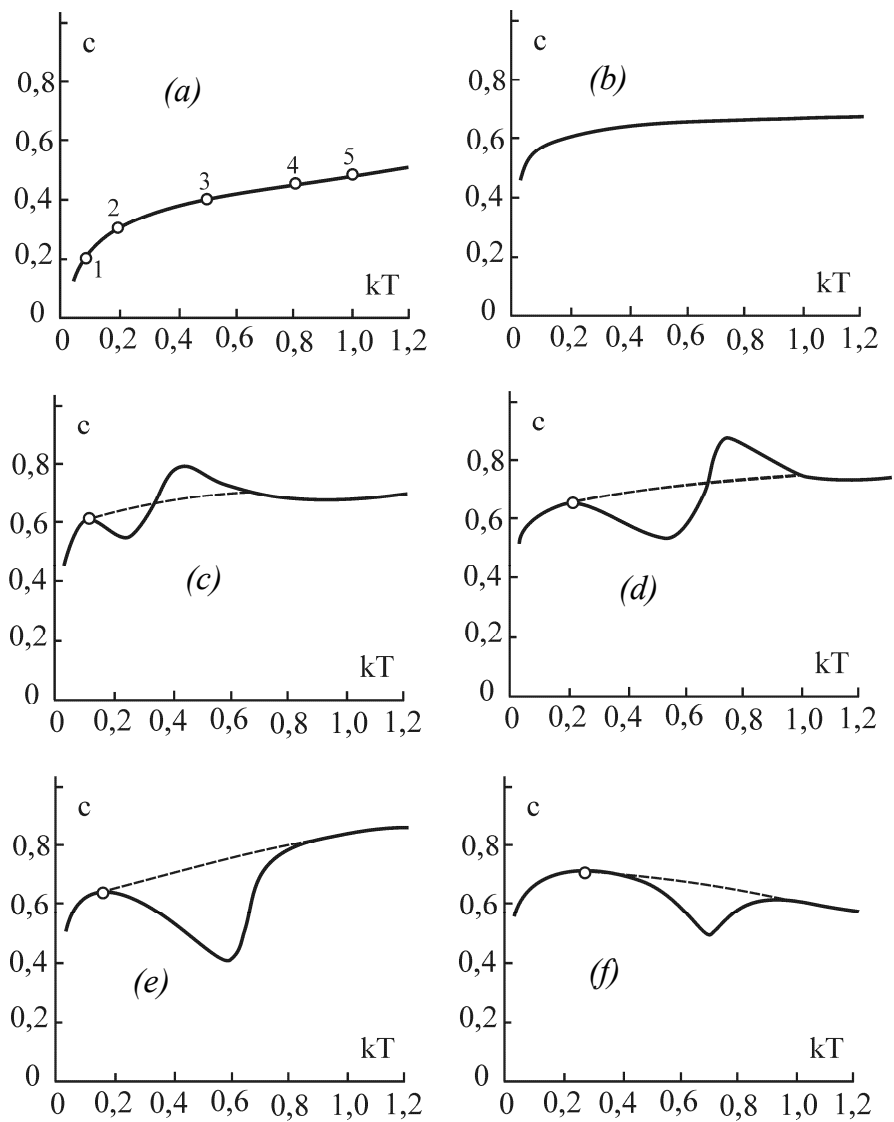

Figure 3 The plots of temperature dependence of fullerenes concentration in the monomolecular film on the crystal surface, constructed by formula (23) for energies $v_{\Phi}, v_{M}$, respectively equal to (in $\mathrm{eV}$ ):
a) $-0,03 ; 0,01 ;$ b) $-0,6 ; 0,1 ;$ c) 0,$36 ;-0,22$;
d) 0,$66 ;-0,45$; e) 0,$72 ;-0,45 ;$ f) 0,$87 ;-0,61$

\section{CONCLUSION}

The elaborated statistical theory of the process of fullerenes deposition on the metallic substrate permits to explain and justify the possibility of manifestation of processes both of fullerenes adsorption and desorption on the crystal surface. It has been shown that passing of each process is defined to a large extent by the character and degree of interaction between fullerenes and atoms of metallic substrate. At weak this interaction the concentration of adsorbed fullerenes increases with a rise in temperature. As this takes place, initially the more intense rise of adsorbed fullerenes has been going on, this 
growth further decelerates and the curves of fullerenes concentrations $\mathrm{c}(\mathrm{T})$ become flat. The fullerenes desorption can manifests itself in a certain temperature range (cases $(c),(d),(e)$ Fig. 3) or will be a continuous at $\mathrm{T}>\mathrm{T}_{\mathrm{m}}$ (case (f) Fig. 3), if interaction of fullerenes with the substrate atoms are sufficiently strong and have the repulsive character.

The established in calculations processes of adsorption and thermodesorption with a temperature rise manifest themselves experimentally with fullerenes deposition on the face (100) of molybdenum crystal [16] and theoretical results are in qualitative agreement with experimental data.

\section{ACKNOWLEDGMENT}

The work has been done within the framework of SCOPES project «Implementation in East Europe of new methods of synthesis and functionalization of carbon nanotubes for applications in the energy storage and sensors field»

\section{REFERENCES}

[1] Chen T., Howells S., Gallagher M., Yi L., Sarid D., Internal structure and two-dimensional order of monolayer $\mathrm{C}_{60}$ molecules on gold substrate, J. of Vacuum Science and Technology B, Vol. 9, № 5, 1991, pp. 2461-2465.

[2] Li Y.Z., Chander M., Partin J.C., Weaver J.H., Adsorption of individual $\mathrm{C}_{60}$ molecules on $\mathrm{Si}$ (111), Phys. Rev. B, Vol. 45, № 23, 1992, pp. 13837-13840.

[3] Rut'kov E.V., Tontegode A.Ya., Usufov M.M., Gall N.R., Carbon diffusion between the volume and surface of (100) molybdenum, Tech. Phys., Vol. 47, № 4, 2002, pp. 484-490.

[4] Young KuK, Kim D.K., Suh Y.D., Park K.H., Noh H.P., Oh S.J., Kim S.K., Stressed $\mathrm{C}_{60}$ layers of $\mathrm{Au}$ (001), Phys. Rev. Lett, Vol. 70, № 13, 1993, pp. 1948-1951.

[5] Kim D.K., Suh Y.D., Park K.H., Noh H.P., Kim S.K., Oh S.J., Kuk Young, Electronic and geometric structure of $\mathrm{C}_{60}$ molecules on $\mathrm{Au}$ (001), J. of Vacuum Science and Technology A, Vol. 11, № 4, 1993, Part II. pp. 1675-1679.

[6] Wertheim G.K., Buchanan D.N.E., Reaction of $\mathrm{C}_{60}$ with metals: W, Sol. St. Commun., Vol. 88, № 2, 1993, pp. 97-100.

[7] Rut'kov E.V., Tontegode A.Ya., Grushko Yu.S., Auger spectroscopy of a fullerite film on an iridium surface, JETP Lett, Vol. 57, № 11, 1993, pp. 724-732.

[8] Sato T., Sueyoshi T., Iwatsuku M., Multilayer growth process of $\mathrm{C}_{60}$ on a $\mathrm{Si}$ (111) surface, Surf. Sci. Lett., Vol. 321. 1994, pp. L137-L142.
[9] Chen D., Sarid D., Grown of $\mathrm{C}_{60}$ films on silicon surfaces, Surf. Sci., Vol. 319, 1994, pp. 74-82.

[10] Hashizume T., Motai K., Wang X.D. et al., Intermolecular structures of $\mathrm{C}_{60}$ adsorbed on the $\mathrm{Cu}$ (111) surface studied by the field ion scanning tunneling microscope, J. Vacuum Sci. Technol. A., Vol. 12, № 4, 1994, pp. 2097-2100.

[11] Rut'kov E.V., Tontegode A.Ya., Usufov M.M., Gall H.R., Carbon interaction with heated molybdenum surface, Appl. Surf. Sci., Vol. 78, № 2, 1994, pp. 179-184.

[12] Rut'kov E.V., Tontegode A.Ya., Usufov M.M., Evidence for a $\mathrm{C}_{60}$ monolayer intercalated between a graphite monolayer and iridium, Phys. Rev. Lett., Vol. 74, № 5, 1995, pp.758-760.

[13] Beton P.H., Dunn A.W., Moriarty P., Beton P.H., Room temperature manipulation of $\mathrm{C}_{60}$ molecules on a $\mathrm{Si}$ surface, Surf. Sci., Vol. 361/362, 1996, pp. 878-881.

[14] Gall N.R., Rut'kov E.V., Tontegode A.Ya., Usufov M.M., Intercalation of two-dimensional graphite films on metals by atoms and molecules, Mol. Mat., Vol. 7, 1996, pp. 187-190.

[15] Gall N.R., Rut'kov E.V., Tontegode A.Ya., Usufov M.M., Using $\mathrm{C}_{60}$ molecules for deep carbonization of zhenium in ultrahigh vacuum, Tech. Phys. Lett., Vol. 23, № 12, 1997, pp. 911-912.

[16] Gall N.R., Rut'kov E.V., Tontegode A.Ya., Usufov M.M., Interaction of $\mathrm{C}_{60}$ molecules with a(100) Mo surface, Tech. Phys., Vol. 44, № 9, 1999, pp. 1066-1068.

[17] Smirnov A.A., Teoria splavov vnedreniya, Moscow: Nauka, 1979, 388 p.

[18] Matysina Z.A., Zaginaichenko S.Yu., Schur D.V., Physical phenomena and properties of crystal surface, Dnepropetrovsk: Nauka i obrazovanie, 2004, 296 p.

[19] Girifalco L.A., Molecular properties of $\mathrm{C}_{60}$ in the gas and solid phases, Journ. Phys. Chem., Vol. 96, 1992, pp. 858-861.

[20] Bezmelnitsin V.N., Eletskiy A.V., Okun M.V., Fullerenes in solutions, Uspehi fizicheskih nauk., Vol. 168, 1998, pp. 1195-1220.

[21] Matysina Z.A., Zaginaichenko S.Yu., Schur D.V., Orders of different type in crystals and phase transformations in carbon materials, Dnepropetrovsk: Nauka i obrazovanie, 2005, $524 \mathrm{p}$.

[22] Smitlz K.J., Metals (Handbook), Moscow: Metallurgiya, $1980,448 \mathrm{p}$.

[23] Shultse G., Metallophysics, Moscow: Mir, 1971, 504 p.

[24] Gripon C., Legrand L., Rosenman I., Boue F., Study of undersaturated $\mathrm{C}_{60}$ solutions in CS2 by small angle neutron scattering, Sci. and Technol., Vol. 4, № 6, 1996, pp. 1195-1270. 